\title{
DESIGN AND DEVELOPMENT OF INTELLIGENT ELECTRONICS TRAVELLING AID FOR VISUALLY IMPAIRED (IETA-VI)
}

\author{
Umar Shuaibu $^{1}$, H. K. Verma ${ }^{2}$, Rabiu Aliyu Abdulkadir ${ }^{3}$, C. Mohan ${ }^{4}$ \\ ${ }^{1 \& 3}$ PG Student Dept. of Electrical \& Electronics Eng. Sharda University, Greater Noida, UP, India \\ ${ }^{2}$ Distinguish Prof. Dept. of Electrical \& Electronics Eng. Sharda University, Greater Noida, UP, India \\ ${ }^{4}$ Assistant Prof. Dept. of Electrical \& Electronics Eng. Sharda University, Greater Noida, UP, India
}

\begin{abstract}
The dynamic nature of the environment poses a big challenge to the visually impaired in navigation. This compels most of the visually impaired persons in the developing countries, who generally do not get any technology support, to depend on the visual sense of others, thus, undermining their independence.

The intelligent electronic travelling aid for the visually impaired (IETA-VI) designed and developed by the authors and reported here, intends to provide solution to the navigational challenges of the visually impaired individuals. The system utilizes the ultrasonic detection technology for detecting any obstacle in his/her path, and then converts the distance to the obstacle into voice using voice synthesis technology so as to inform the visually impaired user. The device uses GPS and GSM technologies to determine the location of the user and to send this location to his/her care givers on mobile phone, respectively. The device also recognizes the voice signals of the visually impaired when in distress, by making use of voice recognition technology and send SMS to his care givers giving his location and asking them to help him.

In a moment of emergency, when the visually impaired requires the attention of his/her care givers, the device provides three alternatives: The first alternative it provides is an emergency key, which when pressed will automatically send the location of the visually impaired to the care givers. The second alternative is that the visually impaired shouts (gives a voice command), the device responds by sending the location of the visually impaired to the care givers. The third alternatives take care of the situation when the user is unconscious or cannot even speak. This is provided by the display device, which displays the names and contact details of his/her care givers, so that someone can offer a helping hand.
\end{abstract}

KEYWORDS: Ultrasonic detection, Voice recognition, Voice synthesis, GPS, GSM.

\section{INTRODUCTION}

Human eye is like a camera that receives and focuses light into the retina, which then stimulates the cells that carry the signal to the brain; without retina, eye cannot see, hence the visual impairment. The visual impairment is the severe reduction of vision that cannot be corrected with the standard glasses or contact lenses, thereby reducing the person's ability to function at certain level [1].

The ever growing number of the people with visual disability, and their continues reliance on the visual sense of others especially in the developing countries serve as an impetus to this research work report in this paper; which intends to design and develop the intelligent electronic travelling aid to aid the navigation of the visually impaired in both the indoor and the outdoor environment.

\section{RELATED WORKS}

Over the years, there has been an evolution of various techniques of guiding visually impaired persons, thus, toward attaining their self-independent by freely moving around their environment without guidance from others; some of these are:

i. Smart walking stick by Mohammed H. Rana and Sayemil ( 2013):
This is based on ping sensor for detecting obstacle, wet electrode, vibration motor and the buzzer. The obstacle is detects by the ping sensor and the obstacle distance is communicates to the visually impaired by the vibration of the motor [2].

ii. The electronic travelling aid for blind navigation and monitoring by Mohan M.S Madulika S. et al (2013): This is arm7 controller based that used ultrasonic technology for detecting the obstacle and inform the obstacle distance to the visually impaired, and also used the GPS and GSM technologies for localization of the visually impaired [3].

iii. New indoor navigation for the visually impaired using visible light communication by Madoka Nakajima and Shinichiro Haruyama (2013):

This is a study that used light fidelity (LI-FI), in this study, the authors propose using visible light communication to help guide the visually impaired in the indoor environment. The visible light communication technology utilises the capability of the led lamps to be probe at a rate faster than the human eye can detect, as such data transmission can be achieved while providing the illumination [4].

iv. Multi-dimensional walking aid by Olakanmi. O. Oladayo (2014): This used ultrasonic detection technology and the voice module, the obstacle is detects by the ultrasonic sensor and the direction of the 
obstacle is communicates to the user through voice output [5].

v. 3D ultrasonic stick for the blind by the Osama Bader Al-Barm (2014):

The system uses ultrasonic sensor for detecting the obstacle in three directions (i.e front, left and the right sides of the visually impaired), and the vibration motor which vibrate with the intensity depending on the obstacle's distance. It also uses GPS and GSM for localization of the visually impaired [6].

In this paper, design and development of intelligent electronic travelling aid for visually impaired is presented. The device employs ultrasonic detection, GSM, GPS, voice recognition and voice synthesis technologies. The design process comprises of two parts; the first part is the obstacle detection and voice generation unit design using ultrasonic detection technology and voice synthesis technology respectively, and the second part is the localization and monitoring unit design using GPS technology GSM technology, as well as the voice recognition technology. The two units are then combines to form the complete device.

\section{TECHNOLOGIES USED}

For the development of intelligent electronic travelling aid for visually impaired (IETA-VI) reports in this paper, the following technologies are use:

\subsection{ULTRASONIC DETECTION TECHNOLOGY}

Ultrasonic detection mimics the innate echolocation capability of bat and dolphin; bat and dolphin make high frequency sound (in ultrasonic range) that bounce off whatever is in front of them. They receive these sounds and can sense the size, shape, density, distance and even texture of an object, this enable them to recognize their target, their prey and predators.

The ultrasonic sensor detects objects by emitting a short ultrasonic burst and then listening for an echo under the control of a host microcontroller; it emits a short eight 40 $\mathrm{kHz}$ burst of ultrasound energy. This burst travels through the air, hits an object and then bounces back to the sensor. The sensor provides an output pulse to the host controller that terminate when the echo is detect; hence the width of this pulse represent the distance to the target. Fig 1 is obstacle detection diagram by the ultrasonic sensor [7].

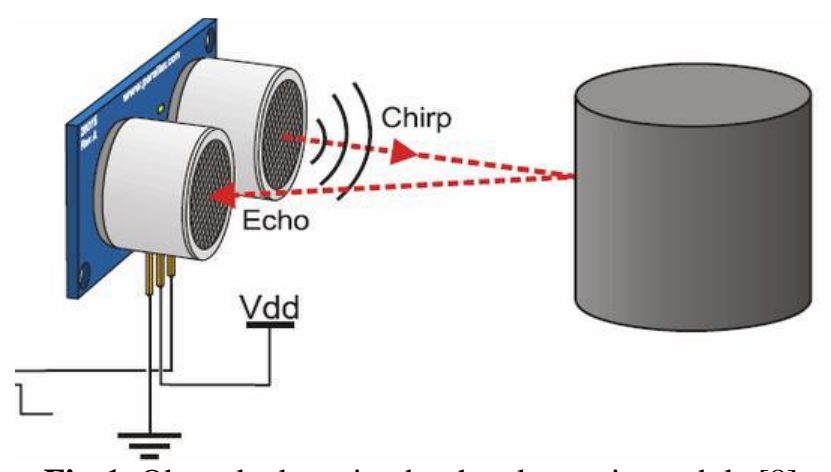

Fig-1: Obstacle detection by the ultrasonic module [8]

\subsection{GLOBAL POSITIONING SYSTEM (GPS) TECHNOLOGY}

Global positioning system is the satellite base navigation consisting of a network of twenty four satellites placed in an orbit; these satellites circle the earth twice a day, transmitting the information to the earth GPS receiver. Basically the GSP receiver determine the four variables which are: longitude, latitude, height and time, additional information can be drive from these four components [9]. Fig 2 is the diagram of the GPS receiver used in this research.

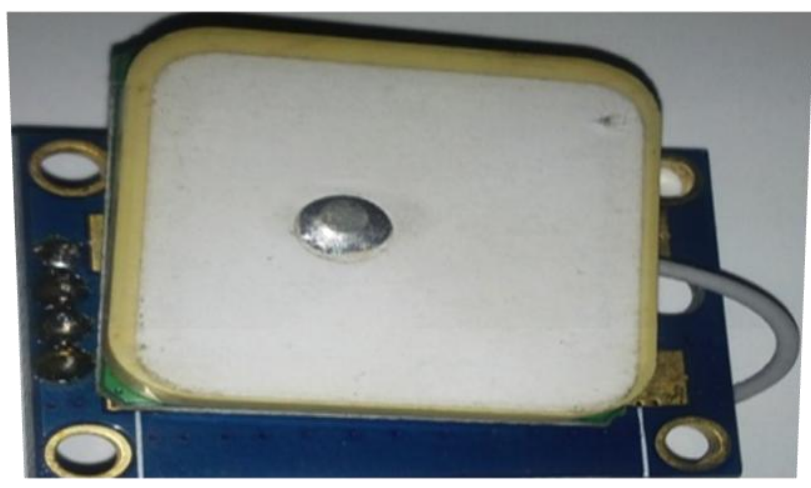

Fig-2: GPS module used

\subsection{GLOBAL SYSTEM FOR MOBILE (GSM) COMMUNICATION TECHNOLOGY}

In the early 1980s, there was analogue communication technique, where by each country developed its own system, this was problematic because the system work only within the boundary of each country. To this end, global system for mobile communication was developed by the conference of the European posts and telecommunication, prior to which exist a number of incompatible systems throughout Europe. The GSM was developed with the main aim of improving efficiency, international roaming, and compatibility with the international subscriber dialing and other telephone company [10]. Fig 3 is the diagram showing GSM module used in this research work which uses GSM technology for communication between the IETA-VI and the care givers.

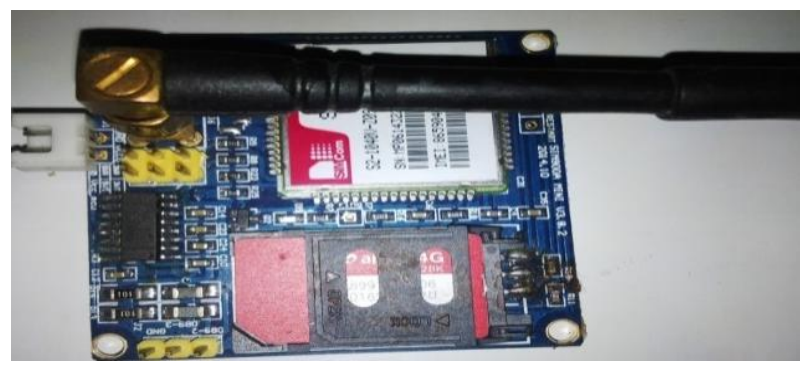

Fig-3: GSM module used

\subsection{VOICE RECOGNITION TECHNOLOGY}

The ability of a machine or software program to identify word or phrases, and convert them into a format that is readable to the computer or other machine is what is termed 
as voice recognition. The voice recognition processes start with the pre-processing of the voice signal; and then follows by feature extraction of the voice signal.

First the speech analog signal is converts into digital form; this then follows by the silence removal where by the silences in the various location of the speech signal are remove. When the silences in the signal are removed, the signal is then boost so as to amplify its low frequency content, this is called pre emphasis. The speech signal then is block into frames of $N$ samples using windowing technique and then the features of each samples of the signal are then extracted. The last stage is the feature matching where by the system unmatched the unknown user from the already known user; and matched the already known user, when this happen, the voice is said to be recognized or not recognized [11].

\subsection{VOICE SYNTHESIS TECHNOLOGY}

The most importance quality of speech synthesis is the naturalness and intelligibility, the naturalness refers to how closeness the generated speech is to the actual human voice; and the intelligibility is the ease to which the synthesized speech is understood. The speech generation or the speech synthesis is the artificial production of human speech; speech can be synthesized by different techniques, but the primary methods are:

a) Articulatory synthesis that attempt to mimic the human articulatory system directly.

b) Concatenate synthesis that uses pre-recorded samples of voice drive from human speech as well as the

c) Formant synthesis that uses the pole frequency of the speech signal, or the transfer functions of the vocal tract [12].

\section{DESIGN AND BLOCK DIAGRAM}

In the development of this system, the Arduino mega2560 development board is selected because of it flexibility, simplicity and most importantly its four serial communication ports.

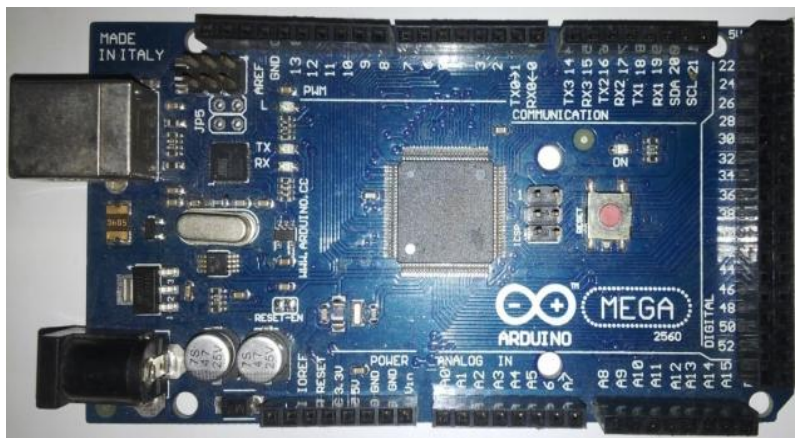

Fig-4: Arduino mega2560 development board

Considering the requirement at hand, Atmega8 is also uses to handle the obstacle detection and the voice generation part of the system. This is necessary due to the complexity of the system; and the amount of delay requires in producing the voice output (around 3-6 seconds); within which many events may happen that the controller cannot notice. Fig 5 below shows the block diagram of the system.

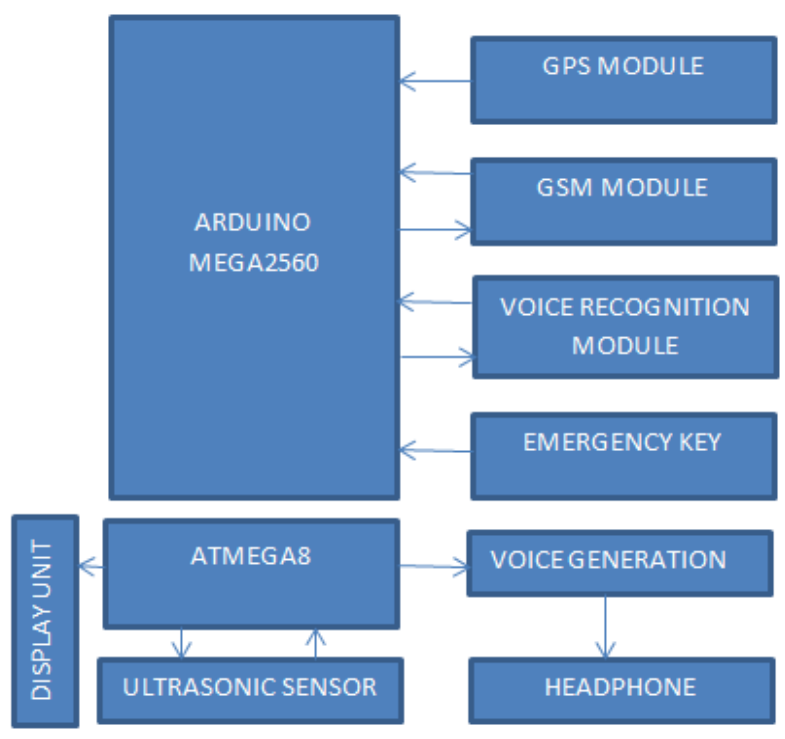

Fig-5: Block diagram

The design of this system is divided into two parts which are obstacle detection and voice generation unit design; as well as the monitoring and localization unit design.

\subsection{OBSTACLE DETECTION AND VOICE GENERATION UNIT DESIGN}

The obstacle detection is handles by the ultrasonic module under the control of the host controller. First the start pulse of 10 micro-seconds duration is given by the controller to the ultrasonic module; this is the obstacle detection initialization process. The ultrasonic module then transmit eight consecutive ultrasonic bursts each of $40 \mathrm{kHz}$ frequency; these bursts travel in search of the obstacle, if detected, the transmitted energy is reflect back to the sensor as an echo.

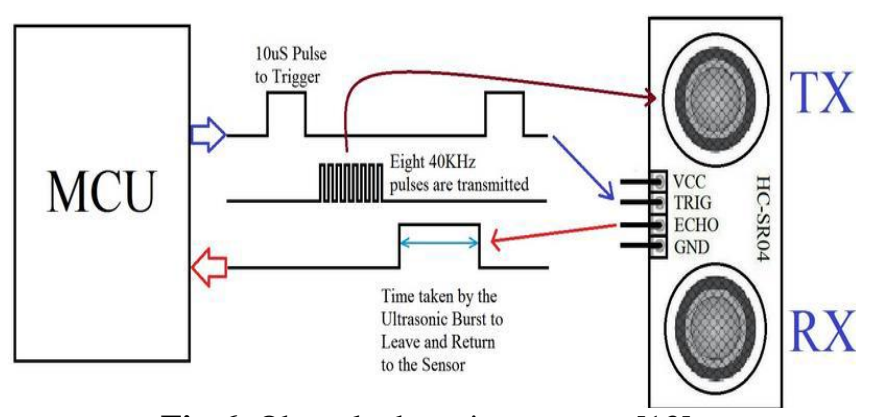

Fig-6: Obstacle detection process [13]

The host controller then listens to this echo; the width of the echo represents the distance to the obstacle; the controller applies the following technique to determine the obstacle's distance from the width of the echo. 


$$
\begin{aligned}
& \begin{array}{l}
\text { speed of sound in air } \\
\text { total distance distance travelled by the pulses }
\end{array} \\
& \begin{array}{c}
\text { time taken } \\
\text { time take }=\text { width of the echo pulse (in } \text { ?ls) }
\end{array} \\
& \quad \text { total distance travelled } \\
& =\text { to and fro distance travel by the pulses }
\end{aligned}
$$$$
\text { therefore, distace to the nearest obstacle }
$$$$
=\frac{\text { total distance travelled by pulses }}{2}
$$

distance$$
=\frac{\text { speed of sound in air } \times \text { width of echo pulse }}{2} \text { time } \times 10^{-6} \text { time }(\text { in } \mu s) \text {. }
$$$$
=\frac{\text { time } \times 10^{-6}}{2 \times 340}=\frac{\text { time }(\text { in } \mu \mathrm{s})}{58}(\mathrm{~cm})
$$

In this research, the voice output is produce only if an obstacle is detect within the range of ten centimeters to three meters; here, different voices are generate using text to speech conversion process, the differences between the actual distance of the detected obstacle to the voice output distance announced is within $\pm 5 \mathrm{~cm}$ range. Fig 7 below is an example of text to speech conversion process of one of the generated voice.

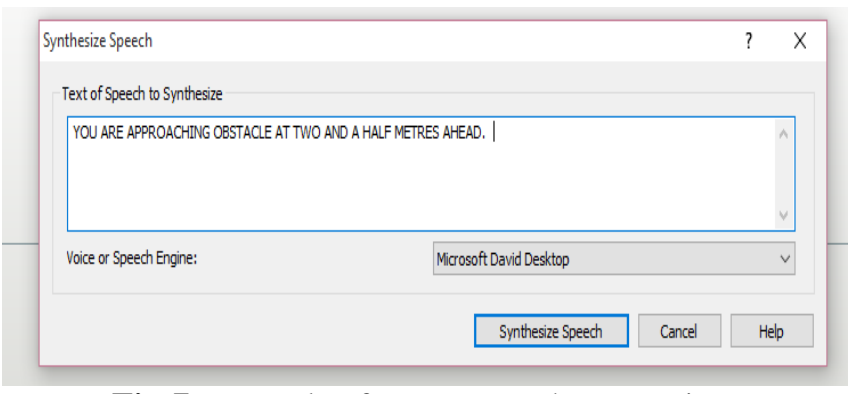

Fig-7: Example of text to speech conversion

Fig 8 is the waveform of the speech signal generated from the text above, which is then amplified with a gain of $400 \mathrm{~dB}$.

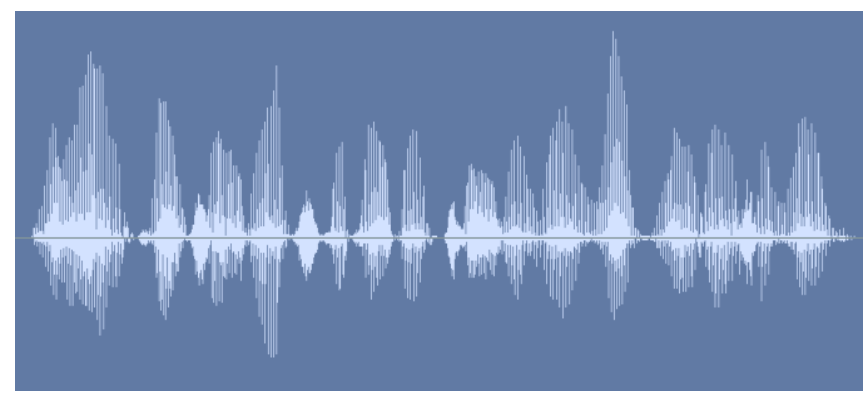

Fig-8: Speech waveform generated

The speech is sample at $44.1 \mathrm{KHz}$ and store as uncompressed 8-bit mono wav-file in the micro SD card. Fig9 below shows wav audio player which play the wav files generate using text to speech conversion technique shown above.

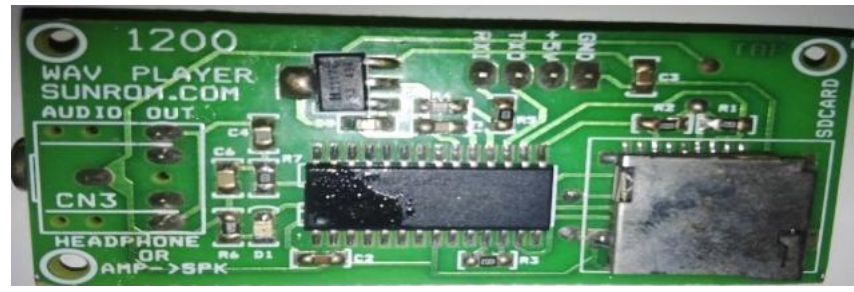

Fig-9: Wav audio player from the SD card

\subsection{MONITORING AND LOCALIZATION UNIT}

\section{DESIGN}

This unit comprises of voice recognition module, GSM module, emergency key as well as the GPS module. The emergency key is connected to an interrupt pin of the controller which serve to interrupt the controller when pressed, thereby making the controller to service the interrupt (i.e sending the location of the visually impaired to the care givers and calling them to help).

The voice recognition module receives the configuration command and response through the serial interface.

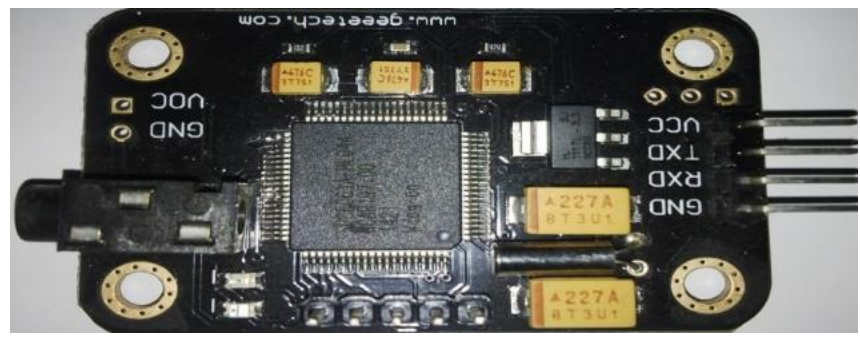

Fig-10: Voice recognition module used

The process for the operation of the voice module is divided into two phases.

The first is the training phase in which the module is train with the voice instruction, it can store up to fifteen instruction that are divide into three groups, each group can be select through the serial interface, in this research only group one instructions are use.

The second phase is the recognition phase, where by the module is made to recognize the voice instruction it is train for, each group has to be import for the system to recognize the instruction in that group. During the training phase, the module configuration is first perform; where by a serial commands are send to the voice recognition module, informing it about the communication baud rate, module response mode, as well as the group to train for voice recognition. Fig 11 shows the arduino and voice recognition module setup for training and recognition phase.

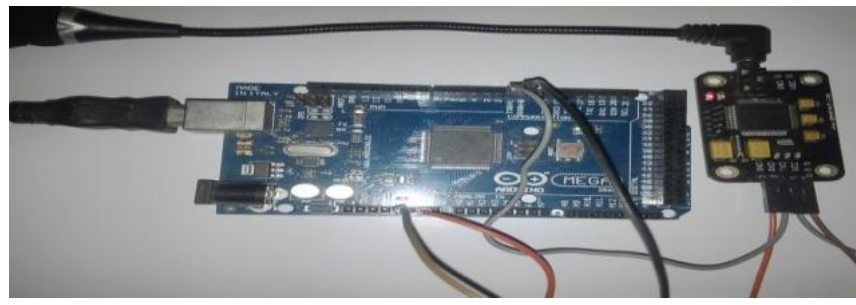

Fig-11: Voice training and recognition setup with the arduino 
After configuration, the first voice instruction is given to the module, same instruction is repeats again for the second time, after which the module response and gives information about whether the two command matches, if it doesn't, the module ask for the repeat of same command until it matches; when the commands matches, the next voice instructionwithin that group is then proceed. This process continues until all the voice instructions in that group are train; the voice recognition is language independent, which means the module can be train to recognizes instructions irrespective of the language use; as testify by some of the instructions which are in native Hausa language of the northern part of Nigeria, as well as the Hindi language of India.

After the training, then the recognition session begins; first the serial command is send to the module informing it that we are into recognition phase. For any group to be recognize, that group has to be import; thus group one is imports for recognition using serial command; in the recognition phase, the voice is feed into the voice recognition module and the module response by giving the sequence of strings corresponding to that instruction; table 1 shows all the five instructions in group one.

Table-1: Voice instruction table

\begin{tabular}{|l|l|}
\hline SN & INSTRUCTIONS \\
\hline 1 & Help! \\
\hline 2 & Help me Dad! \\
\hline 3 & Some body help me! \\
\hline 4 & Wayyo ataimakamin! ${ }^{5}$ \\
\hline 5 & $\begin{array}{l}\text { मेरी मदद करो6 } \\
\text { Mērīmadadkarō! }\end{array}$ \\
\hline
\end{tabular}

5 Hausa language (native language of northern part of Nigeria) which means oh! Help me

${ }^{6}$ Hindi language (widely spoken language in India) which mean help me.

The GPS module is then program and integrated into the system to receive the GPS data.

GSM module uses the GSM network for communication between the IETA-VI and the care giver/s of the visually impaired through short messages. The arduino controller communicate with the GSM module using AT command, the module is test with the AT command using terminal software to confirm it condition this is shown in figure 12 . The module is then program to send and receive messages from the mobile phone and route these messages to the microcontroller for further processing.

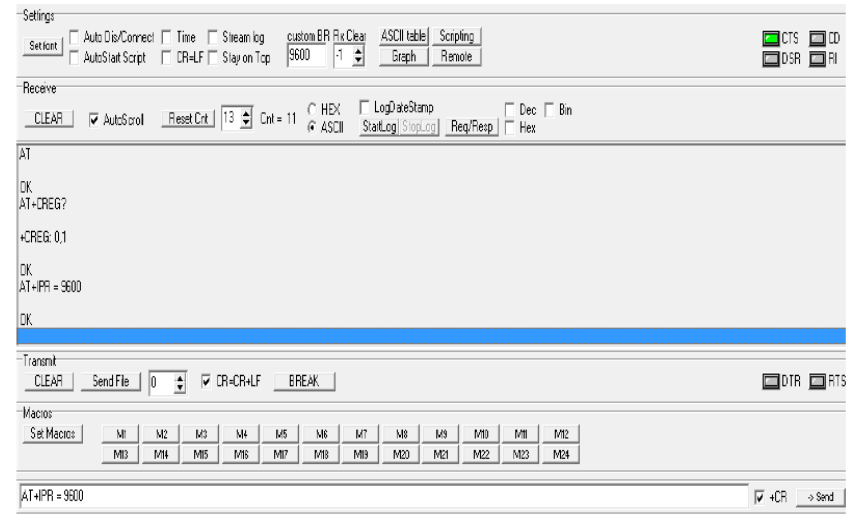

Fig-12: Checking the GSM module working condition

\section{CIRCUIT DIAGRAM}

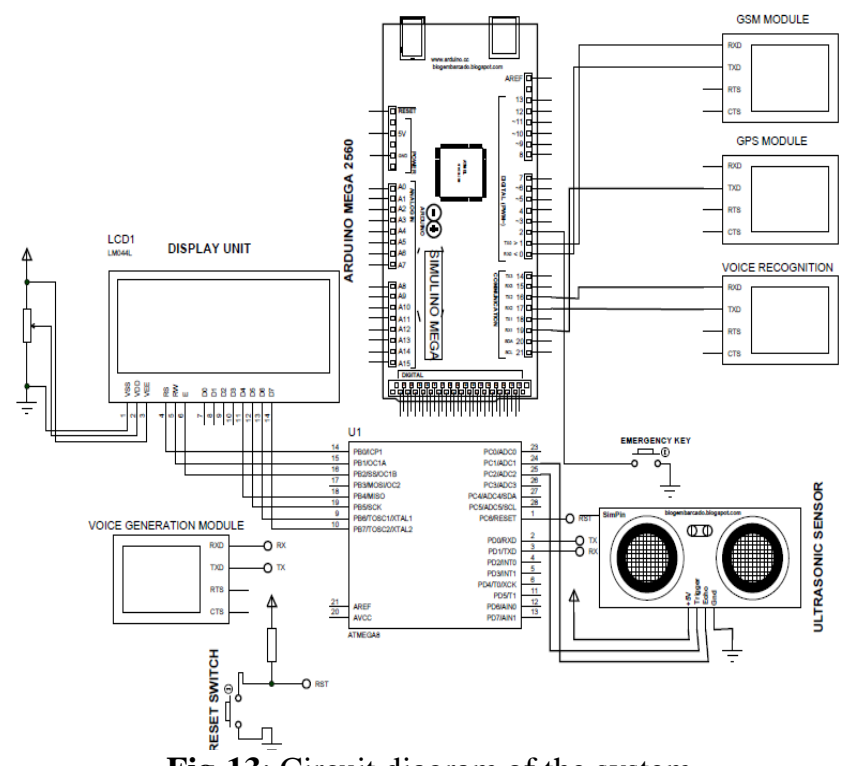

Fig-13: Circuit diagram of the system

\section{FLOW CHART OF THE SYSTEM}

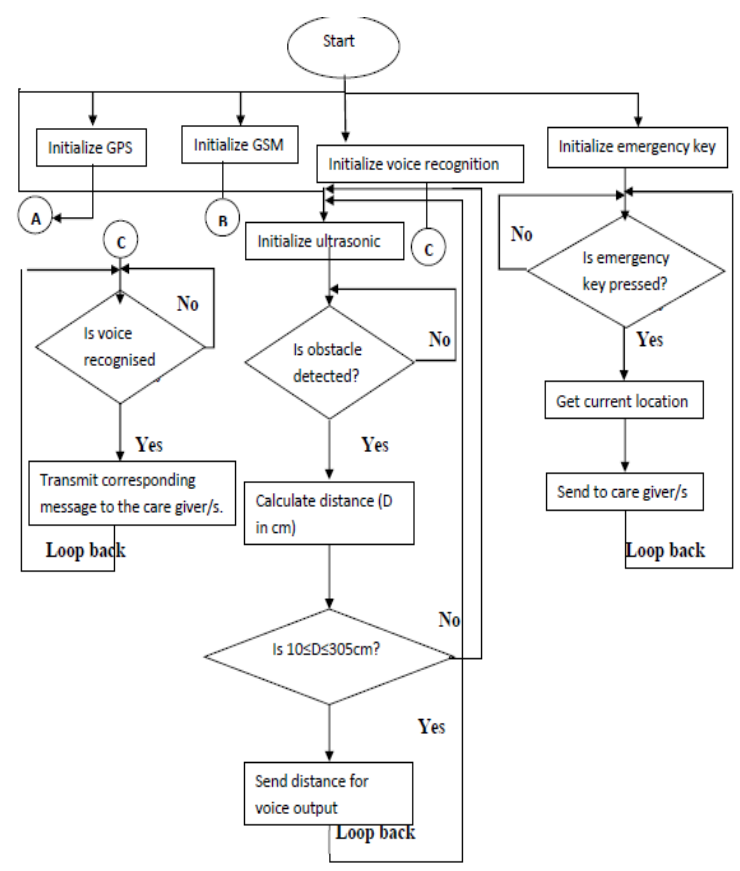




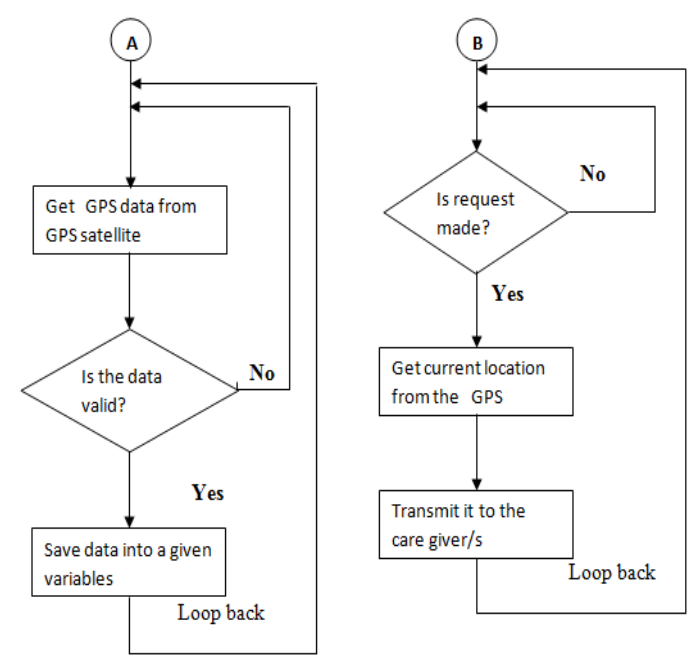

Fig-14: System flow chart

\section{OPERATION OF IETA-VI}

The intelligent electronic travelling aid for visually impaired (IETA-VI) is a device consisting of multiple technologies intends to help toward the independent living of the visually impaired persons. Its operation can be explains in two parts as follows:

a) The first part is the obstacle detection and voice generation unit; this part of the system is responsible for detecting the obstacle in the path of the visually impaired, and informing the visually impaired person about the obstacle and the distance to that obstacle through the voice output.

b) The second part of the system consisted of GPS module, GSM module, emergency key as well as the voice recognition module. When the visually impaired is not at home, and the care givers may like to know his/her location; to this end, the care giver/s can send a request to the IETA through their mobile phone. The IETA is program to recognizes only two requests from the care givers which are:

i. Location, in which the care givers will send a request by texting "*LOCATION\#" from their mobile phone to the IETA and

ii. Get location, where by the care givers will send a request by texting "GET_LOCATION\#" to the IETA.

When the correct request code is receive by the IETA, it will responds by getting the current location of the visually impaired from the GPS; and send the GPS data to the care givers using GSM. When the visually impaired person is in a situation that requires the urgent attention from his/her care givers; to this end, there are two options available to him/her which are:

1) The emergency key: here the visually impaired will request for the help from the care givers; by simply pressing the emergency key which will automatically send the visually impaired location to the mobile phone/s of the care givers.

The second is the voice recognition system: here, the visually impaired will give the voice command to the IETA-VI, the system will recognizes his/her voice instruction; and will automatically send his/her location to the care givers.

\section{PERFORMANCE EVALUATION OF IETA-VI}

The performance evaluation of this system starts by evaluating the performance of the components forming the system. First ultrasonic sensor performance is determine and is obtain to be quite amazing as given in fig 15 considering the three meters detection range that the system intends to work with. Different measurements are taken using the ultrasonic sensor and the result are display in the arduino serial monitor (in centimeters); each measure distance is then compare with the distance measure using scale and the result is find to be the same.

The voice generation module is then integrate, and the appropriate code for playing the obstacles' distances detect is upload into the controller; and it is observe thatthe obstacle detection and voice generation unit work as expected with only \pm 5 centimeters deviation between the actual distance of the obstacle and the voice output distance announce.

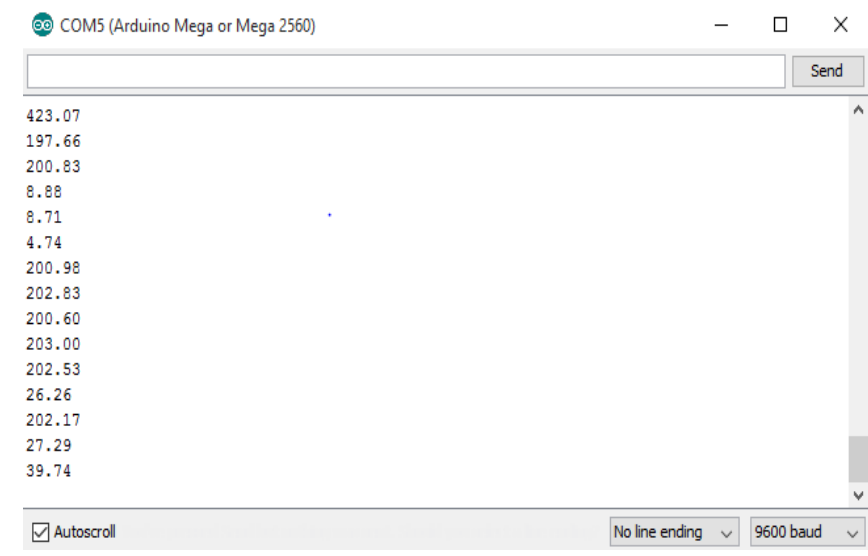

Fig-15: Ultrasonic sensor output

GPS module performance is then test by getting the GPS data of my location and displaying it on the serial monitor; the latitude and longitude obtain is then compare with the actual latitude and longitude of that location and the result is find to be correct as shown in fig 16

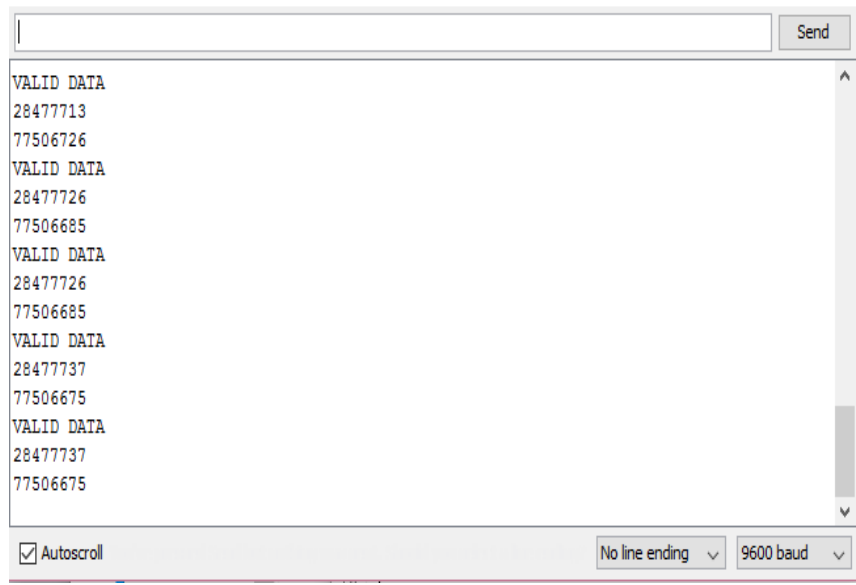

Fig -16: GPS data obtained during performance testing 
Voice recognition module is then tested after it is train; the group one instructions is imports and then test by feeding the voice instruction for that group. When the module recognizes the instruction, it gives an output representing that instruction.Fig17 is the result obtain from voice recognition module for all the five instructions in group one.

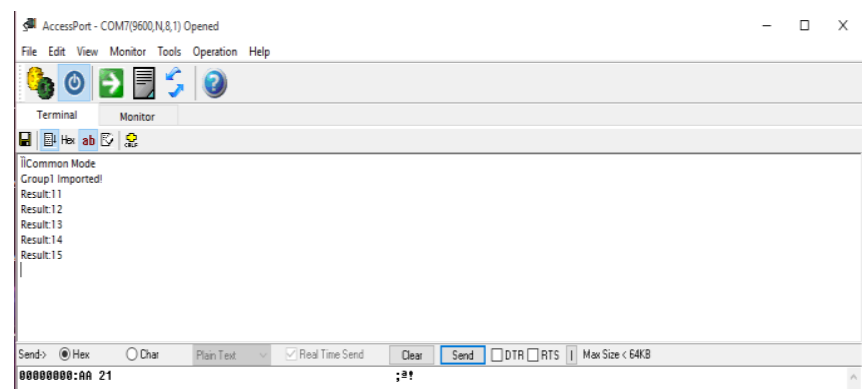

Fig-17: Simulation for the recognition of the voice instructions

Fig-17: Simulation for the recognition of the voice instructions.

Table-2: Meaning of the result obtain in fig17 and the recognize instructions

\begin{tabular}{|l|l|l|l|}
\hline Sn & Result & Meaning of the result & $\begin{array}{l}\text { Recognized } \\
\text { instruction }\end{array}$ \\
\hline 1 & $0 \times 11$ & $\begin{array}{l}\text { First instruction of } \\
\text { group one is recognized }\end{array}$ & Help! \\
\hline 2 & $0 \times 12$ & $\begin{array}{l}\text { Second instruction of } \\
\text { group one is recognized }\end{array}$ & Help me Dad! \\
\hline 3 & $0 \times 13$ & $\begin{array}{l}\text { Third instruction of } \\
\text { group one is recognized }\end{array}$ & $\begin{array}{l}\text { Somebody help } \\
\text { me! }\end{array}$ \\
\hline 4 & $0 \times 14$ & $\begin{array}{l}\text { Fourth instruction of } \\
\text { group one is recognized }\end{array}$ & $\begin{array}{l}\text { Wayyo- } \\
\text { ataimakamin! } !^{5}\end{array}$ \\
\hline 5 & $0 \times 15$ & $\begin{array}{l}\text { Fifth instruction of } \\
\text { group one is recognized }\end{array}$ & $\begin{array}{l}\text { मेरी मदद करो6 } \\
\text { Mērīmadadkarō! }\end{array}$ \\
\hline
\end{tabular}

GSM module performance is lastly evaluate by first using it to send and receive message through the terminal window; and then programming it with the Arduino to send and receive messages, all the result work satisfactorily as shown in fig 18 below.

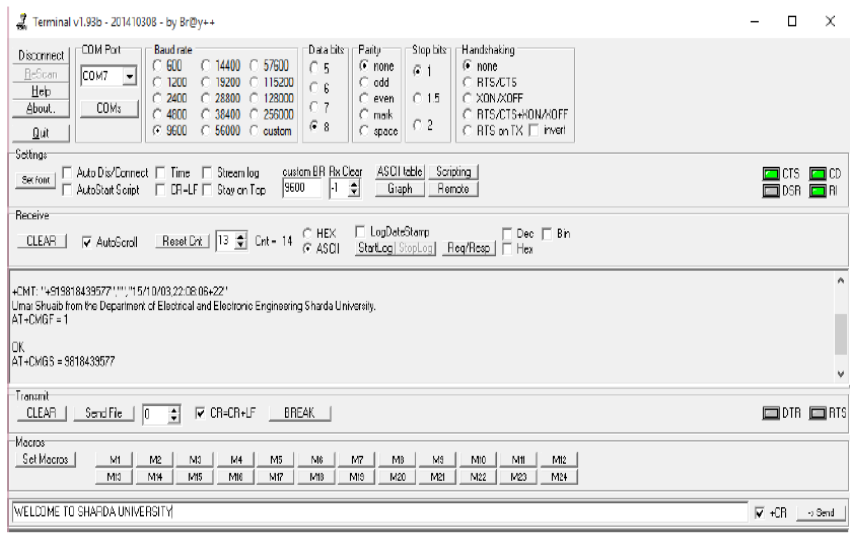

Fig-18: Using terminal window and GSM module for messaging

\section{CONCLUSIONS}

The intelligent electronic travelling aid for visually impaired developed by the authors and reported here intended to improve the ability of the visually impaired to live independently, and to perform his day to day activities easily, and more safely by providing the following functionalities:

a) Providing the voice based information about the distance of any obstacle in the path of the visually impaired.

b) Providing localization and monitoring through GPS, GSM as well as the voice recognition. The device makes use of the following five technologies interactively:
i. Ultrasonic detection technology
ii. Global positioning system (GPS) technology
iii. Global system for mobile (GSM) communication technology
iv. Voice synthesis technology and
v. Voice recognition technology

To further extend the IETA-VI, the following are the recommendations:

i. Addition of the RFID technology to provide the RFID mapping for the indoor environment so as to provide the voice based guidance and localization to the visually impaired in his/her home.

ii. It can also be extended for automation of the home of visually impaired using voice recognition, which is already available in the system, so that the visually impaired can have control over various lights, fans, HVAC system and other appliances in home. This will further enhance his independence inside the home.

\section{REFFERENCES}

[1] Visual impairment: At www.who.int/mediacentre/factsheets accessed on 2015-05$\underline{24}$

[2] Hazaz Mahmud, RanaSaha et al 2013. Smart walking stick.International journal of scientific and engineering research 4(1), 111-114

[3] Mohan M.S, Madulika S. Arm7 based electronic travel aid for the blind people,An International Journal of Research in Computer and Communication Technology 2(12) 1345-1350

[4] Nakajima M. and Haruyana S. (2013): new indoor navigation system for the visually impaired people using visible light communication, EURASIP journal on wireless communication and networking. 1-10.

[5] Olakanmi O. Oladayo: Multidimensional walking aid. International journal of Intelligent Systems and Applications, 2014, 08, 53-59

[6] Al-Barm O.B and Vinouth.(2014) 3D Ultrasonic walking stick for the blind. International Journal of Latest Trends in Engineering and Technology3(3), 108-114

[7]SR04 Ultrasonic sensor datasheet

[8] Ultrasonic sensor: at www.robotronicspro.blogspot.in accessed on 24/05/2015

[9] Ignacio GmesFernadez, GPS space segment monitoring: at www.fenixtechnico.ulisboa.pt .accessed on 25/07/2015 
[10]

GSM-architecture:

at

www.tutorialspoint.com/gsm/gsmarchitectureacessed on $\underline{27 / 07 / 2015}$

[11] Abd-Ghaffar H. Fatma A.M et al (2011) Smart blind stick: Speech recognition; Mansoura University department of electronic and communication.

[12] Wikipedia:Speech synthesis accessed on 20/07/2015

[13] Hc-sr04 sensor: at www.electrosome.com accessed on 20/07/2015

[14] How to measure distance with SR04 ultrasonic sensor: at www.Robotica.webs.upv.es accessed on 20/06/2015

\section{BIOGRAPHIES}

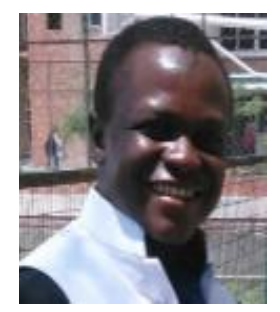

\section{Mr Umar Shuaibu}

PG Student, Instrumentation and control engineering, School of engineering and technology, Sharda University Greater Noida, UP, India.

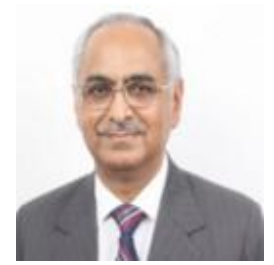

\section{Dr H.K Verma}

Distinguish Professor Department Electrical and Electronics Engineering, School of engineering and technology Sharda University Greater Noida, UP India.

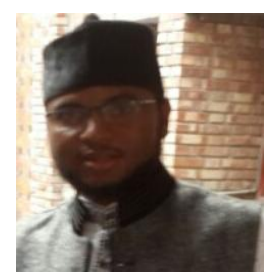

\section{Mr RabiuAliyuAbdulkadir}

PG Student, Instrumentation and control engineering, School of engineering and technology, Sharda University Greater Noida, UP India.

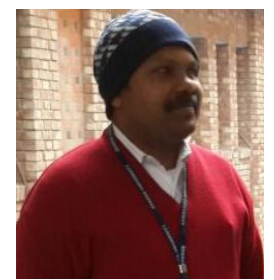

\section{Mohan}

Assistant Professor Department Electrical and Electronics Engineering, School of engineering and technology Sharda University Greater Noida, UP India. 